2. Сорокин, П. А. Человек. Цивилизация. Общество. Москва, 1992. 542 с. (Мыслители XX века).

3. Гидденс, Э. Устроение общества. Очерк теории структурации. Москва, 2005. 525 с.

4. Дюркгейм, Э. Социология. Её предмет, метод, предназначение. Москва, 1995. 352 с.
5. Лефевр A. Социальное пространство // Неприкосновенный запас. 2010. № 2. С. 3-14.

6. Лотман, Ю. М. Семиосфера. СанктПетербург, 2010. 704 с.

7. Савицкий, П. Н. Континент Евразия. Москва, 1997. 461 с.

Olga V. Pervushina, Ph. D. in Cultural Science, Associate Professor Altai State Institute of Culture (Barnaul, Russia) agaki-pervushina@yandex.ru

\title{
CULTURAL SPACE AS “LOCALLY DETERMINED PROGRESS" IN THE CONTEXT OF THE EURASIANISM: A CULTURAL STUDIES PERSPECTIVE
}

\begin{abstract}
The paper describes peculiarities of understanding by the today's humanities and cultural studies a concept 'space' which means physical, social, and symbolic types of reality («text») in interrelation and mutual dependence of their specifics and key features. The author outlines analysis of Eurasianists' views on 'space' phenomenon that expressed through Piotr Savitskii's term «mestorazvitie» (which means «locally determined progress/development» in Russian) that marks in Russian geocultural thought a specific process of spatiotemporal interaction between society and landscape which accommodating it.

Keywords: culture, cultural space, semiosphere, a text, "locally determined progress», social reality, «the Eurasianism», geosocial and geocultural approach.

\section{References}

1. Wade N. Na zare chelovechestva: neizvestnaya istoriya nashikh predkov [Before the Dawn: Recovering the Lost History of Our Ancestors]. Moscow, 2019. 407 p. [In Russ.]

2. Sorokin P. A. Chelovek. Civilizaciya. Obshestvo [A Human. A Civilization. A Society]. Moscow, 1992. 542 p. (Thinkers of the $20^{\text {th }}$ Century). [In Russ.].

3. Giddens A. Ustroenie obshchestva. Ocherk teorii strukturacii [The Constitution of Society. Outline of the Theory of Structuration]. Moscow, 2005. 525 p.

[In Russ.].

4. Durkheim E. Sociologiya. Eyo predmet, metod, prednaznachenie. [Sociology. Its Object, Method, Assignment]. Moscow, 1995. 352 p. [In Russ.].

5. Lefebvre A. Social'noe prostranstvo [Social Space] // Neprikosnovennyj zapas [Emergency Reserve]. 2010. No. 2. Pp. 3-14. [In Russ.].

6. Lotman Yu. M. Semiosfera [Semiosphere]. Saint Petersburg, 2010. 704 c. [In Russ.].

7. Savitskii P. N. Kontinent Evraziya [The Eurasian Contitent]. Moscow, 1997. 461 c. [In Russ.].
\end{abstract}

УДК 008(4/5)

DOI: 10.32340/2514-772X-2019-1-29-34

М. Ю. Спирина, кандидат исторических наук, Университет при Межпарламентской Ассамблее Евразийского экономического сообщества (Санкт-Петербург, Россия) mus931@inbox.ru

\section{БОЛЬШОЕ ЕВРАЗИЙСКОЕ ПАРТНЁРСТВО: ТЕОРЕТИКО-МЕТОДОЛОГИЧЕСКОЕ ОБОСНОВАНИЕ}

Аннотация. Представлен обзор идейно-философских оснований интеграционных процессов, протекающих между современными государствами Евразии в различных сферах хозяйственной, культурной и духовной жизни. Охарактеризован актуальный статус Большого евразийского партнёрства - международного проекта, нацеленного на укрепление экономических и культурных связей между странами евразийского макрорегиона, на гармонизацию экономических интересов ведущих государств крупнейшего в мире материка. Автор предлагает рассматривать универсальные смыслы традиционных культур народов Евразии в качестве ресурса для идейной консолидации субъектов интеграционных процессов. 
Ключевые слова: евразийство, Большое евразийское партнёрство, иенности традиционной народной культуры, Евразия, инновационные центры, европоцентризм, международное сотрудничество.

В 2016 году главный редактор журнала «Россия в глобальной политике» Ф. Лукьянов отмечал: «Евразийский союз переживает очень тяжёлое становление. Масса нерешённых вопросов вкупе с попытками с разных сторон политизировать данное объединение. <...> Реальной альтернативы (евразийской интеграции - М. С.) просто нет <..>. В длительной долгосрочной перспективе евразийский проект неизбежно, хотя не без трудностей, будет развиваться и сопрягаться с китайским Шёлковым путём» [1]. Мнение автора отражало естественный процесс эволюции всей евразийской системы: расширение взаимодействия новых независимых государств Евразии с постоянно наращивающей свою мощь Китайской Народной Республикой, усиление интеграционных тенденций на континенте, включая и противоречивый Европейский союз. Вместе с тем нельзя не упомянуть и возникновение дезинтеграционных проявлений в евразийском пространстве. Исследователи и политики пришли сегодня к выводу, что в результате эволюции должен появиться конгломерат, которому в XXI веке предстоит сыграть роль противовеса евроатлантической системе. Вследствие этого всё шире стала пропагандироваться идея Большого евразийского партнёрства (БЕП). В течение 2016 года концепция БЕП стала флагманской российской инициативой по развитию евразийской интеграции.

Созданный в 2014 году Евразийский экономический союз продолжил выполнение основных целей Евразийского экономического сообщества: формирование согласованной экономической политики и принятие совместных программ стратегического развития. Вследствие такого ограничения интеграционный процесс утратил гуманитарное измерение, что впоследствии поставило на повестку дня необходимость формирования идеологии евразийской интеграции (С. Ю. Глазьев).

В текущем году исполняется 25 лет идее прагматичного евразийства Н. А. Назарбаева, идее стратегической и эффективной. Однако всё острее ощущается потребность в теоретико-методологическом обосновании эволюционирующего интеграционного процесса. И здесь следует обратить внимание на два сущ- ностных аспекта формирования такого обоснования. Первым мы считаем всё ещё сохраняющийся европоцентризм в теоретических исследованиях и практических действиях исследователей, управленцев разных уровней, так называемых «элит» (политической и деловой) и рядовых насельников евразийского континента. Убеждённость в тезисе «Европа нам поможет» давно надела шоры на глаза большинства участников интеграционных объединений. Только сегодня начинают меняться мнения и действия. Исторический опыт показывает, что примитивное копирование европейских идей без их творческой переработки на отечественной почве с учётом национальной специфики, систематически приводит к серьёзным осложнениям. По этим причинам, в частности, Е. Чернышёв называет европоцентризм еврохолуйством [2]. Он считает, что подобное преклонение перед Европой воспитывает плебейскую психологию: прозападно ориентированные индивиды, впитав в себя эту идеологию, не знают ни истории, ни культуры своего народа, но, не зная ничего этого, презирают его в полной убежденности в своей «прогрессивности» и «цивилизованности», заискивая перед Западом и обнажая свою холуйскую сущность [2].

Подобные проявления фиксируются и в обыденном сознании обитателей евроазиатских просторов. Смена ценностных ориентиров оказала неблагоприятное воздействие на развитие азиатских и африканских государств во второй половине XX века: нарушилось духовное единство общества, изменились жизненные приоритеты молодого поколения, что сопровождалось утратой традиционных ценностей, деформацией традиционных для той или иной страны моральных норм и нравственных установок. Эти явления отрицательно повлияли на общественную нравственность, гражданское самосознание, на отношение людей к обществу, государству, закону и труду, на отношение человека к человеку. Постепенно многие, если не все, из новых государственных образований Евразии (центральноазиатских и восточноевропейских) осознали опасность утраты национального самосознания, культурной самобытности, угрозы нацио- 
нальной безопасности. В марте 2016 г. участники обсуждения темы «Европоцентризм в истории и исторической науке» подчеркнули, что европоцентризм, который прослеживается в исторической науке уже не одно столетие, весьма серьёзно формирует сознание людей по всему миру и накладывает свой негативный отпечаток. Преклонение перед Европой, как правило, приводит к утрате национальных целей и перспектив. По мнению Д. В. Калюжного, сегодня европоцентризм является одним из элементов информационной войны [3]. И здесь мы обращаемся уже ко второму аспекту формирования теоретикометодологического обоснования Большого евразийского партнёрства - к роли традиционной культуры в жизнедеятельности современных государственных образований.

В поисках способов противостояния европейско-американскому влиянию новые независимые государства обратились к традиционным ценностям, сохранившимся в традиционной культуре евроазиатских народов. Полагаем, что традиционные ценности выступают, прежде всего, как ценности национальные, народные, национальноэтнографические, национально-религиозные. Они обладают базовым, фундаментальным, основополагающим, системообразующим характером.

Традиционная культура сегодня рассматривается как образ жизни. Напомним здесь известные слова А. С. Пушкина: «Гордиться славою своих предков не только можно, но и должно; не уважать оной есть постыдное малодушие». Великий русский поэт считал: «Европа в отношении России всегда была столь же невежественна, как и неблагодарна. Озлобленная Европа нападает покамест на Россию не оружием, но ежедневной бешеной клеветою. $<\ldots>$ С изумлением увидели мы демократию в её отвратительном цинизме, в её жестоких предрассудках, в её нестерпимом тиранстве. Всё благородное, бескорыстное, всё возвышающее душу человеческую - подавлено неумолимым эгоизмом и страстию к довольству» [5, с. 165].

Традиционные ценности можно определить как ДНК общественного и государственного развития. При разработке концепции культуры В. С. Стёпин обратил внимание на то, что в современном культурном тексте сохраняются такие исторические феномены, как «мировоззренческие универсалии». Он назвал их культурно-генетическим кодом и разделил на две группы: в одну включил категории «природа», «космос», «пространство», «время»; в другую - категории «справедливость», «добро», «красота», «человек» и т.д. [6, с. 6061]. По его мнению, «мировоззренческие универсалии выполняют в жизни общества такую же функцию, как и гены в живом организме. Они организуют в целостную систему сложнейший набор различных феноменов культуры и выступают в качестве базисных структур социокода, играют роль своего рода ДНК социальной жизни».

Понятие «традиционная культура» вбирает в себя всю совокупность материальной и духовной деятельности, выражающей нераздельность связи человека с природой. Этот вид культуры существует как организованная форма трансляции ценностей, как фиксированная память человечества о самом себе. Сначала президент РФ В. В. Путин, а затем президент Казахстана Н. А. Назарбаев сочли необходимым обратиться к традиционным ценностям как важной компоненте эволюции современного человека, общества и государства. Духовно-нравственные ценности включены в Стратегию национальной безопасности Российской Федерации. Яркий пример обращения к традиционной культуре в современном мире показывает Китайская Народная Республика, в которой, как писал академик М. Л. Титаренко, традиционная культура стала «частью комплексной мощи Китая, обеспечивающей $<\ldots>$ защиту от внешней пропаганды и внешнего проникновения» [4]. Традиционная культура предоставляет возможности поддерживать и развивать взаимопонимание различных народов, а также противодействовать этнической и религиозной ненависти, насилию, сепаратизму и другим формам экстремизма, способствовать развитию гражданского общества. Вследствие этого в начале третьего тысячелетия КНР стала играть существенную роль в формировании и эволюции разнообразных интеграционных процессов на евразийском континенте.

Взаимодействие народов и культур всегда являлось значимым фактором общественноэкономического развития. Базисом этого взаимодействия выступали именно традиционные ценности (духовно-нравственные, трудовые, бытовые, эстетические). Традиционная куль- 
тура содержит исторический опыт правосознания, хозяйствования, общественного делания, искусства, развития нравственности, что позволяет поддерживать и поощрять взаимопонимание как внутри одного общества, государства, так и среди различных народов. Традиционной культуре присущи коллективность, синкретизм, традиционность, преемственность, историзм. Отечественные учёные рассматривают традиции как живой, способный к саморазвитию, а не стереотипный, «мёртвый», похожий на шаблон, феномен. Синкретичный характер традиционной культуры проявлялся в слиянности общечеловеческого и национального, материального и духовного компонентов жизнедеятельности человека; единстве науки и практики. Сегодня использование опыта синкретизма традиционной культуры выступает важнейшим фактором достижения универсальности содержания образования и позволяет осуществлять воспитание субъекта этноса как представителя целостной биосоциальной системы, что трудно переоценить при обеспечении безопасности жизнедеятельности человека и укреплении человеческого капитала евразийских стран. Сохранение, распространение и развитие традиционной национальной культуры следует рассматривать как приоритетное направление в системе обеспечения национальной безопасности евразийских государств.

В процессе формирования теоретикометодологического обоснования Большого евразийского партнёрства особое внимание следует обратить на практически неизученную народную философию. Г. С. Виноградов так охарактеризовал её: «Народная философия - это большая рукопись из неопределённо большого количества не пронумерованных листов, разнесённых ветром по земле» [7, c. 8]. Традиционная культура начала формироваться с первобытных времен, но интерес к её формам, видам, результатам эволюции проявился у представителей различных отраслей научного знания только в XX в. Древние памятники, относящиеся к эпохе первобытности, находились и изучались археологами. Часть предметов и явлений стала объектом изучения этнографов. Отдельные компоненты анализировались социологами, педагогами, потом искусствоведами. Но со стороны философов к традиционной культуре внимания не проявлялось. Вместе с тем, традици- онная культура являет собой поле для трансдисциплинарных исследований, поскольку она непосредственно связана с материальным производством, с природной средой и со всей социальной практикой народных масс, с их общественным и семейным бытом, с обычаями, со всем укладом жизни.

Народная мудрость - это не поэтическая метафора, а сложная и развитая философскомировоззренческая система, отражающая важнейшие стороны жизни человека и этноса в их отношениях с природой и себе подобными, но выраженная не в форме философских трактатов, а в сложном комплексе мифологических, религиозных представлений, стиле мироотношения, многожанровом фольклорном творчестве. Для проведения системного, комплексного анализа этого феномена необходимо преодоление «ведомственной разграниченности» современного гуманитарного знания, что определяется синкретизмом традиционной культуры. Народная философия должна явиться отдельным направлением научного поиска и практического применения в современной реальности [8].

Президент России неоднократно подчеркивал: «Духовное единство народа и объединяющие нас моральные ценности - это такой же важный фактор развития, как политическая и экономическая стабильность <...> и общество лишь тогда способно ставить и решать масштабные национальные задачи, когда у него есть общая система нравственных ориентиров, когда в стране хранят уважение к родному языку, к самобытной культуре и к самобытным культурным ценностям, к памяти своих предков, к каждой странице нашей отечественной истории» [9]. Для того чтобы проект Большого евразийского партнёрства стал ожидаемой реальностью, необходимо значительно активизировать научное изучение всего исторического опыта традиционной культуры и её сущностных компонентов. К исследованиям и пропаганде их результатов необходимо привлечь представителей различных сфер культуры, искусства, образования, социальные институты, средства массовой информации, радио, телевидение, общественные организации. Проблемы изучения, сохранения и эволюции традиционной (народной) культуры на сегодняшний день требуют особо пристального внимания и соединения усилий различных органов власти, учреждений и организаций куль- 
туры, искусства и образования, усилий общества и отдельных личностей.

Традиционная культура (традиционные ценности) должна сыграть ведущую роль в формировании нового евразийского экономико-культурного ландшафта, сохранении национального (и регионального, и континентального) культурного наследия, обеспечении социально-исторической и духовногенетической преемственности поколений. Проблему обращения к опыту традиционной культуры смогли бы решить комплексные инновационные центры, созданные в каждом крупном регионе России и отдельных странах евразийского континента. Подобные центры будут способствовать объединению усилий акторов в сфере хозяйствования, образования, науки, искусства, социокультурной деятельности по сохранению и актуализации традиционных ценностей, содержащихся в традиционной культуре, по формированию идеологической основы регионального интеграционного процесса. Особую сферу деятельности таких инновационных центров должна составлять профессиональная подготовка специалистов в области традиционной культуры и разработка инновационного содержания образовательной деятельности разноуровневых образовательных учреждений, где осуществляется подготовка управленцев, педагогов, экономистов, искусствоведов, философов, художников-мастеров, дизайнеров, социальных работников и др. Такие высокопро- фессиональные специалисты смогли бы претворить в реальность интеграционные инициативы евразийских государств, в том числе и прежде всего идею Большого евразийского партнёрства.

\section{Список литературы}

1.Лукьянов $\Phi$. Евразийский союз будет меняться. URL: http://eurasia.expert/fedor-lukyanovevraziyskiy-soyuz-budet-menyatsya (Дата обращения 05.01.2017).

2. Чернышёв Е. Преодолеть европоцентризм. URL: https://nstarikov.ru/blog/21215 (05.01.2015).

3.Европоцентризм через призму мировой и российской истории. URL: http://ujmos.ru/ evropotsentrizm-cherez-prizmu-mirovoy-i-rossiyskoyistorii (дата обращения 05.01.2017).

4.Титаренко М. Л. Китай: цивилизация и реформы. Москва, 1999. С. 159-228.

5.Пушкин А. С. Джон Тёрнер // Собрание сочинений. Москва, 1962. Т. 6: Критика и публицистика. С. 164-190.

6.Стёпин B. С. Цивилизация и культура. Санкт-Петербург, 2011. 407 с. (Классика гуманитарной мысли).

7.Виноградов Г. С. Народная педагогика. Иркутск, 1926. $30 \mathrm{c}$.

8. Спирина М. Ю. Традиционная культура и народная философия // Национальная философия в глобальном мире. Минск, 2017.

9. Путин В. В. Послание Федеральному Собранию Российской Федерации 26 апреля 2007 года. URL: http://kremlin.ru/events/president/transcripts/ 24203 (21.01.2019).

Marina Yu. Spirina, Ph. D. in History University of Inter-Parliamentary Assembly of the Eurasian Economic Community (Saint Petersburg, Russia) mus931@inbox.ru

\title{
THE GREAT EURASIAN PARTNERSHIP: THEORETICAL AND METHODOLOGIC GROUND
}

\begin{abstract}
The paper reviews ideological and philosophical foundations of integrational process run between modern states of Eurasia in various spheres of economic, cultural, and spiritual life. The current stats of The Great Eurasian Partnership aimed at strengthening of economic and cultural relations between countries of the Eurasian macro-region, at reconciliation of economic interests of the most powerful states from the biggest continent of the Earth is characterized. The author of the paper offers to consider Eurasian peoples' cultures' identical senses in the capacity of resource for ideological consolidation of actors of integrational processes.
\end{abstract}

Keywords: Eurasianism, the Great Eurasian Partnership, values of traditional people's culture, Eurasia, innovation centers, eurocentrism, international collaboration. 


\section{References}

1. Luk'yanov $F$. Evrazijskij soyuz budet menyat'sya [The European Union will be changed]. URL: http://eurasia.expert/fedor-lukyanov-evraziyskiysoyuz-budet-menyatsya/ (05.01.2017). [In Russ.].

2. Chernyshyov E. Preodolet' evropocentrizm [To Overcome Eurocentrism]. URL: https:// nstarikov.ru/blog/21215 (05.01.2015). [In Russ.].

3. Evropocentrizm cherez prizmu mirovoj i rossijskoj istorii [Eurocentrism through the Prism of the World And Russian History].

URL: http://ujmos.ru/evropotsentrizm-cherez-prizmumirovoy-i-rossiyskoy-istorii (дата обращения 05.01.2017). [In Russ.].
4. Titarenko M. L. Kitaj: civilizaciya i reformy [China: Civili[In Russ.].zation and Reforms]. Moscow, 1999. Pp. 159-228.

5. Styopin V. S. Civilizaciya i kul'tura [Civilization And Culture]. Saint Petersburg, 2011. 407 p. [In Riss.].

6. Vinogradov G. S. Narodnaya pedagogika [Ethnic Pedagogics]. Irkutsk, 1926. 30 p. [In Russ.].

7. Spirina $M . Y u$. Tradicionnaya kul'tura i narodnaya filosofiya [Traditional Culture and Peoples' Philosophy] // Nacional'naya filosofiya $\mathrm{v}$ glo-bal'nom mire [National Philosophy in Global World]. Minsk, 2017. [In Russ.]. 